\title{
FUNGSI GARIS PADA DESAIN DAN SKETSA
}

\author{
Lintang Widyokusumo \\ Desain Komunikasi Visual, School of Design, Binus University \\ Jln. K. H. Syahdan No. 9, Palmerah, Jakarta Barat 11480 \\ lintangw@binus.edu
}

\begin{abstract}
In the early stages of designing a design, sketch is an initial beginning of the creation of a powerful idea. Preliminary sketch forms structured or free lines to try to catch an idea or a model that will be realized in the design or picture. The process behind the stunning design starts from a dot and lines to the structure and expanded into a variety of alternative designs. The role of a line is often underestimated and exacerbated by the increasingly rapid development of technology, which makes people lazy to explore manually. The strength of line/scratch built through a continuous training process produces bold, spontaneous, and characterized lines.
\end{abstract}

Keywords: line, conture, character

\begin{abstract}
ABSTRAK
Pada tahap awal merancang sebuah karya, sketsa menjadi sebuah awal bermulanya ide kreasi yang dahsyat. Sketsa awal berbentuk garis-garis berstruktur ataupun bebas mencoba untuk menangkap ide ataupun model yang akan diwujudkan dalam desain ataupun gambar. Proses di balik desain yang memukau diawali dari sebuah titik dan garis menjadi struktur dan meluas menjadi alternatif desain yang beragam. Peran garis sering diremehkan dan diperburuk dengan perkembangan teknologi yang makin pesat, yang membuat malas untuk bereksplorasi secara manual. Kekuatan sebuah garis/goresan dibangun melalui proses latihan yang menerus menghasilkan sebuah garis yang berani, spontan, dan berkarakter.
\end{abstract}

Kata kunci: garis, kontur, karakter 


\section{PENDAHULUAN}

Seorang perancang komunikasi visual profesional sangat penting untuk mengerti prinsipprinsip desain yang membedakannya dengan perancang amatir. Perancangan komunikasi visual tidak hanya membuat sebuah visual tampak sekedar bagus dan atraktif, tetapi juga jika pesan yang disampaikan akan sampai pada khalayak sasaran.

Memahami prinsip-prinsip desain tentunya akan membantu perancang untuk menyampaikan pesan yang dimaksud tersebut dengan pendekatan yang atraktif, informatif, dan menarik. Prinsip desain adalah: kontras, irama, aksen, simetris/asimetris

Dalam perancangan desain, selain memerhatikan prinsip-prinsip desain,diperlukan elemenelemen desain dalam proses perancangannya. Apabila dikonotasikan sebagai seorang chef, elemen desain adalah bahan-bahan memasaknya.Dengan demikian, prinsip desain adalah resep mengolah masakan tersebut sehingga dicapai hasil masakan yang nikmat dan sesuai dengan selera konsumen.

Adapun elemen desain adalah: garis, titik, warna, bidang, pattern, texture, dsb. Dalam penulisan kali ini akan dibahas salah satu elemen desain, yaitu garis. Garis mempunyai peran mendasar yang sangat besar dalam sebuah perancangan desain,karenagaris mempunyai fungsi dominan dalam membentuk ruang, bentuk, kontur, arah, dll.

\section{METODE PENELITIAN}

Artikel disusun berdasarkan studi pustaka, yaitu menyeleksi beberapa sumber referensi baik cetak maupun elektronik, dan melakukan beberapa observasi sketsa berbagai bentuk, bidang, tekstur. Kemudian informasi tersebut dirangkum menjadi dasar penulisan artikel ini.

\section{HASIL DAN PEMBAHASAN}

\section{Peranan elemen Garis dalam Desain}

Untuk penulisan kali ini, akan dibahas salah satu elemen dari desain yaitu garis. Garis terbentuk dari kumpulan titik. Garis merupakan elemen dasar di dalam proses desain. Menggambar adalah salah satu seni visual yang menggunakan garis sebagai dasar utama. Garis tidak mudah ditemui di alam sekitar kita, garis mungkin dapat dijumpai sebagai tepi dari sebuah objek benda ataupun bentuk retakan pada batu atau tembok, garis-garis pada bulu zebra, ranting pohon, dsb.

Garis dalam seni adalah sebagai alat bantu untuk mengenterpretasikan sesuatu. Sebenarnya kita mengenal garis sejak masa kanak-kanak hingga dewasa.Kualitas garis tentunya berubah seiring tumbuh kembang kita.

Dalam proses desain dan hasil akhir sebuah desain, elemen garis banyak digunakan untuk memenuhi fungsi sebagai pembatas bidang, memisahkan isi, mengarahkan arah pandangan, menandai penekanan kata, wireframe dalam perancangan 3D. 


\section{Kontur}

Sebuah kontur adalah sebuah bentuk garis yang membentuk atau mengikat sesuatu. Hampir semua bentuk garis di dalam seni adalah garis kontur. Seperti telah disebutkan di atas, bahwa di alam nyata kita tidak melihat garis kontur disekitar sebuah objek. Bahkan garis kontur tidak hanya diterjemahkan disekeliling objek, tetapi juga ditengah objek untuk menerjemahkan lipatan, kerutan, bahkan perubahan warna.

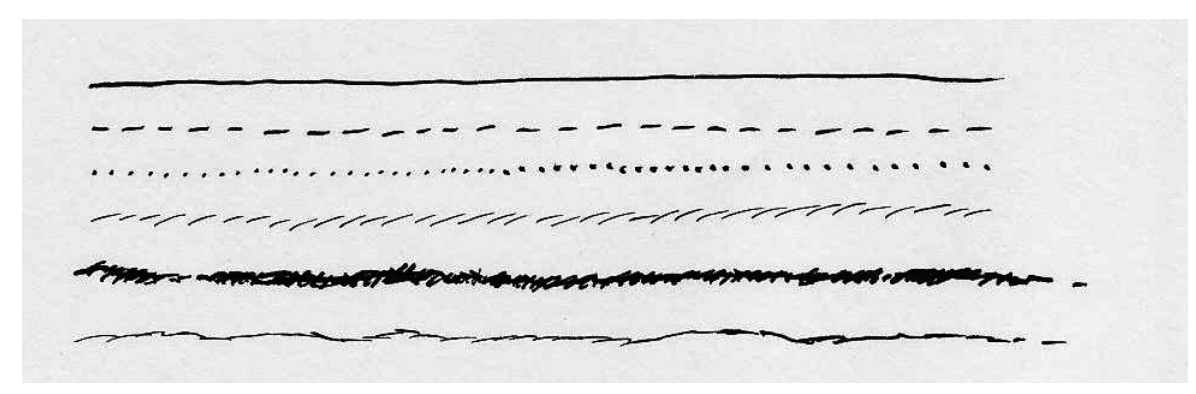

Gambar 1 beberapa garis kontur yang terbentuk dari berbagai macam goresan (Sumber: penulis)

\section{Membagi Bidang}

Garis dapat digunakan untuk membentuk sebuah bidang dan membagi bidang.

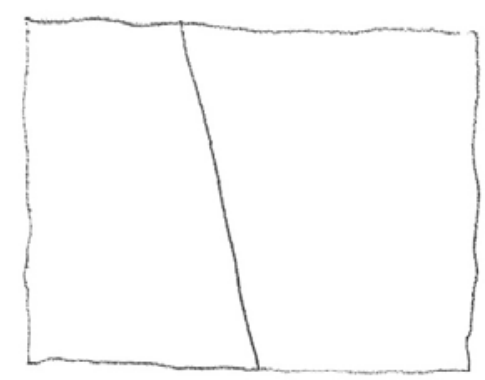

Gambar 2 garis vertikal yang berarti membagi bidang (Sumber: penulis)

\section{Garis Horizontal}

Garis Horizontal dapat menggambarkan cakrawala luas, tenang, aman, dan stabil.

\section{Garis Vertikal}

Garis Vertikal dapat menggambarkan sebuah kekuatan yang menjulang (garis tebal), sekaligus berkesan dingin, religius, dan kebanggaan akan harga diri.

\section{Garis Diagonal}

Berkesan tidak seimbang, namun menggambarkan energi yang melesat, dapat berkesan “jatuh” atau "bangun”. Lebih dramatis dibandingkan dengan garis vertikal/horizontal. 


\section{Garis Lengkung}

Garis lengkung berkesan lunak/cair, tidak terprediksi arah dan tujuan. Kesan tenang sebuah garis lengkung terletak dari seberapa tajam lengkungan garis tersebut.

\section{Garis Zig-Zag}

Adalah kombinasi garis diagonal yang bertemu pada satu titik. Garis ini terlihat dinamis dan mempunyai energi yang tinggi sehingga menciptakan kesan kegembiraan dan gerakan yang intens. Bila arahnya cepat berubah,menciptakan sebuah kesan kebingungan dan kecemasan. Sering juga garis zig-zag menciptakan kesan retak/terbelah.

\section{Garis Dekoratif}

Berbagai macam cara untuk menggunakan garis sebagai alat bantu untuk mendekorasisebuah bentuk. Dekorasi dibutuhkan untuk meyakinkan pelihat bahwa bentuk tersebut adalah sebuah papan kayu dengan seratnya, kain kusut yang tergeletak di meja, gelas bening yang tembus cahaya dll.

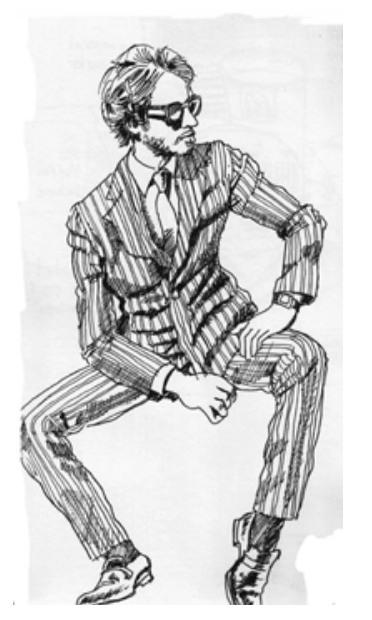

Gambar3 figur model dengan dekorasi pada jas yang dikenakan mengesankan kerutan kain, volume, dan dimensi (Sumber: penulis)

Pemakaian umum dari mendekorasi adalah menambah dimensi, tekstur, atau bayangan dengan membubuhkan garis secara berulang dan bersilang pada bagian-bagian yang dianggap memiliki tekstur atau bayangan akibat sebuah pencahayaan.Selain dapat menerjemahkan dan meyakinkan halhal yang tidak terlihat pada dunia nyata, garis juga dapat berfungsi nyata secara artistik pada sebuah benda untuk memperindah tampilan (seperti sepeda motor yang dihias stiker elemen garis yang sporty merepresentasikan kecepatan, api, atau angin).

\section{Garis Sketsa Gerak}

Merupakan bentuk garis yang cenderung cepat menerus dan kasar yang biasa digunakan artis/desainer untuk menangkap gerak dan bentuk (manusia dan manusia). Biasanya, berwujud garisgaris kasar lalu pada tahapan akhir menggambar ditegaskan kembali dengan kontur garis yang lebih tegas. 


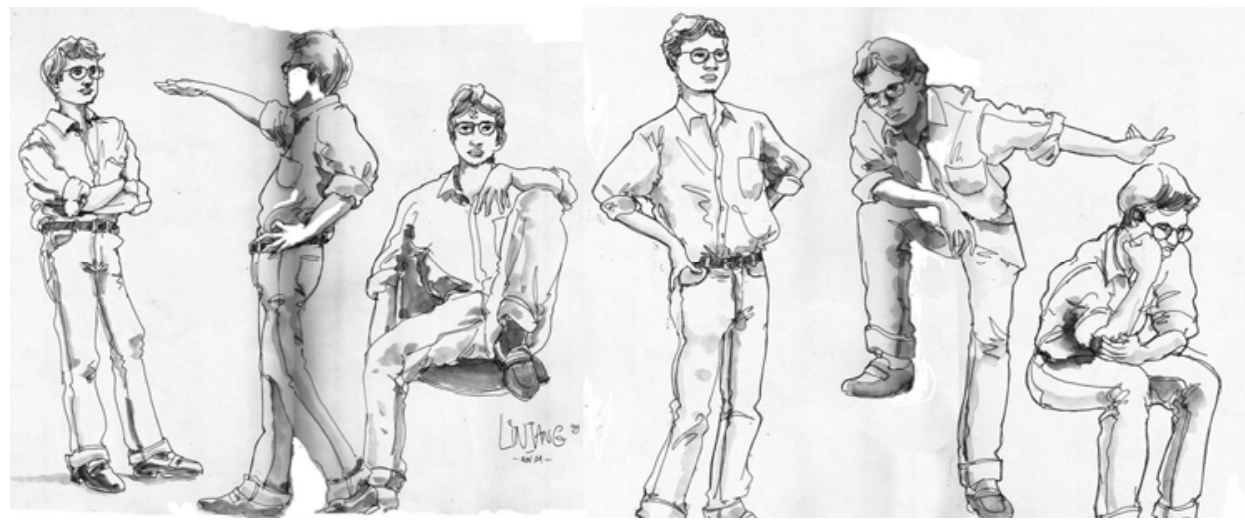

Gambar 5 beberapa sketsa gerak dari seorang model yang terus berubah pose dalam waktu lima menit (Sumber: karya penulis)

\section{Kualitas Garis}

Garis adalah alat komunikasi. Ketika seorang artis atau desainer menggoreskan garis pada sehelai kertas, maka sebetulnya di situlah sebuah cerita dimulai. Garis tidak hanya membuat sebuah cerita, namun juga penyampaian yang meyakinkan dapat diperoleh dari sebuah penggambaran yang mendekati nyata. Kualitas garis pada gambar/sketsa/desain seperti sebuah suara menarik dengan intonasi dan gaya bahasa yang atraktif pada seorang story teller.

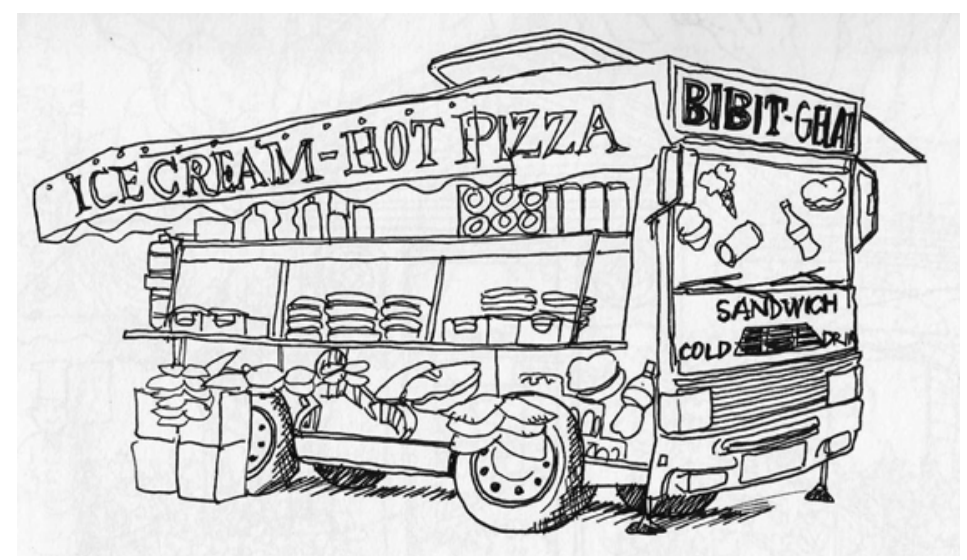

Gambar 6 kualitas garis didapat dari proses latihan sketsa yang menerus sehingga torehan garis terlihat tegas dan kontinu (Sumber: karya penulis)

Kualitas garis didapat dari tebal-tipis, terang-gelap, solid-samar, dan warna dari sebuah garis. Dengan kualitas garis kita dapat membantu pelihat untuk meyakinkan dan merasakan yang lebih penting atau tidak, benda itu bergerak atau diam, berat atau ringan, tekstur kasar atau halus. Kualitas garis menentukan mood dari karya seni tersebut. Bagi seorang master, ekspresi kualitas garis menjadi dasar ekspresi gaya/ciri khas tersendiri. 


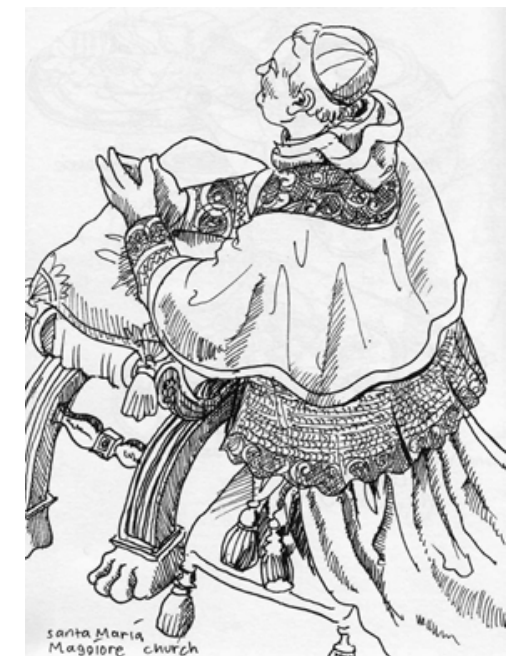

Gambar 7 gaya tarikan/torehan garis menjadi ciri khas masing-masing artisdalam ekspresi karyanya (Sumber: karya penulis)

\section{Ekspresi Kualitas Garis}

Kualitas garis dapat diekspresikan pada berbagai macam aplikasi seni/desain, sebagai contoh

\section{Peta}

Garis digunakan pada desain peta sebagai jalan antar-kota atau rute trayek kendaraan umum.

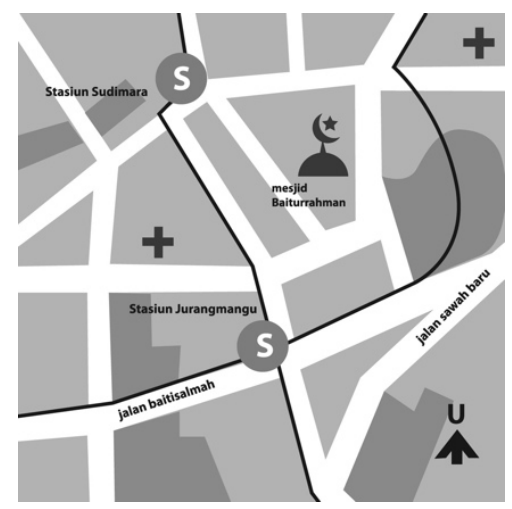

Gambar 8 peta lokasi yang menggunakan garis sebagai tanda jalan raya atau rel kereta (Sumber: penulis)

\section{Layout Ruangan}

Pada layout ruangan garis difungsikan sebagai kontur pembentuk bangunan, kontur tanah, lantai, ilustrasi furnitur dan panah pengukur besaran serta ketinggian ruangan. 


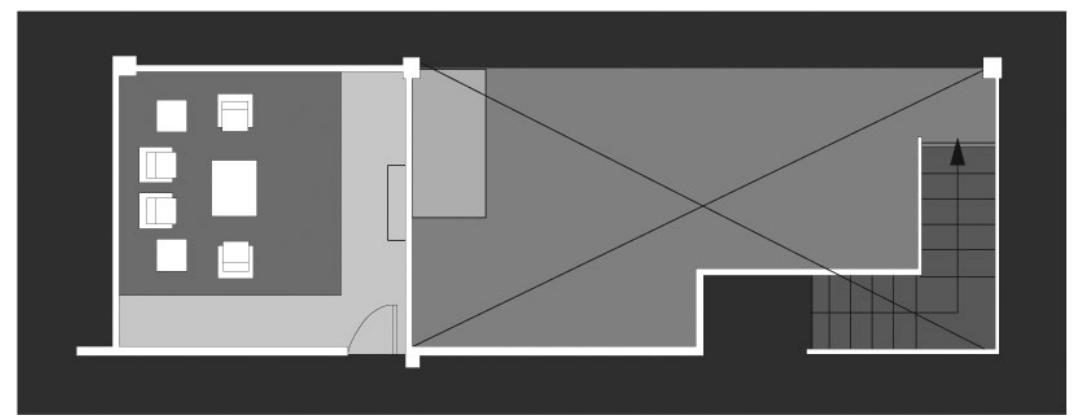

Gambar 9 garis digunakan sebagai pembentuk kontur ruang, lantai dan furnitur (Sumber: penulis)

\section{Grafik}

Garis pada penggambaran grafik dapat berarti kenaikan atau penurunan performa sebuah laporan tahunan atau grafik perkembangan kesehatan seseorang, mengalami penurunan, stagnan atau kenaikan performa.

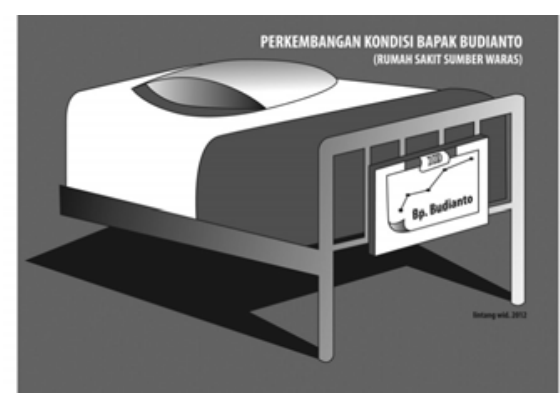

Gambar10 garis digunakan sebagai penggambaran grafik

(Sumber: penulis)

\section{Grid}

Perancangan sebuah buku dimulai pada perancangan struktur tata letak (grid) untuk meletakkan semua elemen desain pada buku (teks, gambar, dan ilustrasi) sehingga tercipta tatanan yang baik untuk dibaca (menyangkut hierarki antar-elemen).

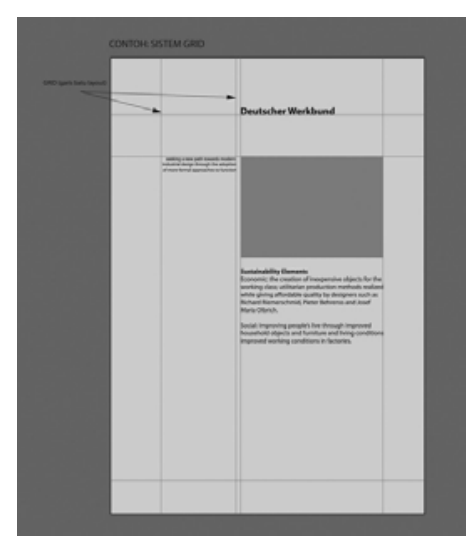

Gambar 11 garis digunakan sebagai struktur grid pada layout buku/majalah (Sumber: penulis) 


\section{Sebuah Proses Menggambar}

Coba cari sebuah objek gambar yang menarik dan tidak banyak bergerak (diam). Amati objek tersebut, kira-kira angle mana yang menarik dan terbaik untuk digambar. Bila objek tersebut mudah dipindahkan, geser benda tersebut pada cahaya yang tepat dan dramatis (terang-bayang) untuk digambar agar dapat didekorasi lebih detail.

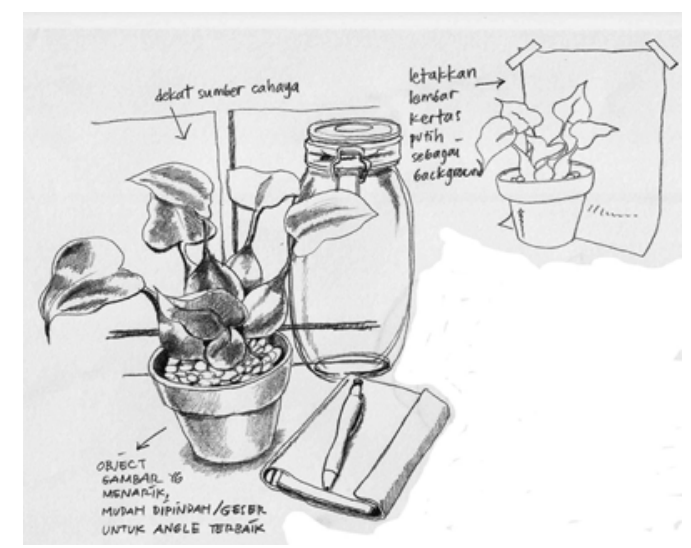

Gambar12: ilustrasi setting sebuah komposisi benda untuk latihan sketsa (Sumber: penulis)

Jika ingin objek terlihat lebih fokus (tidak terganggu oleh background yang tidak perlu) letakkan lembar kertas putih sebagai background. Sesuaikan proporsi benda yang ingin digambar dengan ukuran kertas yang dipakai. Perhatikan bentuk kontur dari objek yang digambar, karena merupakan garis luar yang paling tegas dari garis-garis pendukung di dalamnya (pergunakan garis tipis pada awal sketsa). Perhatikan pengaturan tekanan pensil untuk mengatur gelap-terang, kasarhalus, dsb. Untuk objek gambar benda hidup jangan menggunakan garis yang terlalu kaku dan konstruktif.

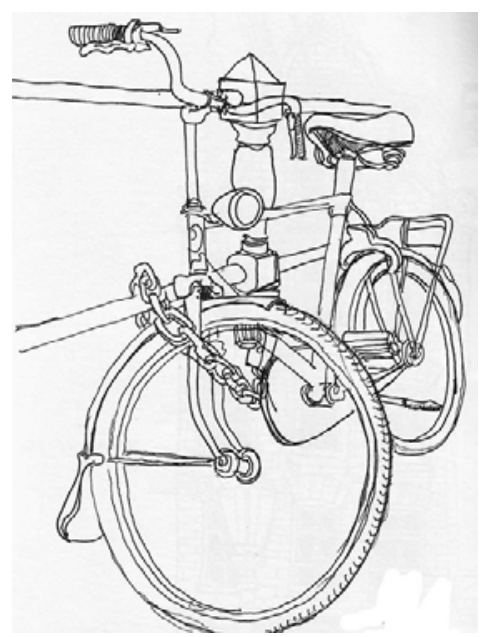

Gambar13 ilustrasi sketsa objek sepeda dengan menggunakan tekanan goresan berbedauntuk membentuk dimensi

(Sumber: penulis) 
Beri jeda sewaktu sketsa kontur untuk selalu melihat kembali objek yang digambar, agar terjaga kemiripan dan proporsi benda tersebut. Bila kemiripan wajah/bentuk sudah tercapai, pertegas garis yang penting sebagai bentuk akhir yang dikehendaki. Arsir bagian-bagian yang dapat memperjelas dimensi dan tekstur dengan menggunakan bermacam kualitas garis.

\section{SIMPULAN}

Garis sebenarnya adalah esensi dari perbendaharaan visual yang dipadukan dengan bentuk, warna, tektur, ruang sebagai media berkomunikasi para artis/desainer. Berbagai macam perwujudan garis mempunyai arti masing-masing. Karakter terbentuknya garis ditentukan oleh kita melalui tekanan goresan sebuah sketsa. Melalui latihan yang kontinu akan melatih goresan artistic pada karakter garis.

Walaupun kemajuan teknologi pada era digital saat ini menawarkan berbagai kemudahan dalam menghasilkan sebuah sketsa digital yang menarik, semua hanya sebagai alat bantu. Artis atau desainer yang sesungguhnya adalah kekuatan garis yang dihasilkan oleh kekuatan tangan dan buah pikiran kita yang dilatih terus-menerus dengan media basic secara manual.

\section{DAFTAR PUSTAKA}

Barrington, B. (2011). The Practical Guide to Drawing Anatomy. London: Arcturus Publishing.

Nigel, H. (2000). Designer’s Guide to Creating Charts \& Diagrams. New York: Watson-Guptil. 